\title{
Fetal Growth Restriction (FGR) - Identification and Management
}

\author{
Jayasundara DMCS
}

\section{INTRODUCTION}

The perinatal morbidity and mortality is an important measuring tool in obstetric health care provision in a country. Of factors that affect the perinatal morbidity and mortality, suboptimal fetal growth is a wellestablished cause for increased perinatal morbidity and mortality (1). It is now known that poor fetal growth may be associated with adverse health conditions and non-communicable diseases in the adult life as well (2). Thus this condition affects obstetrics and paediatrics as well as adult medical and surgical specialities and has a huge impact on the healthcare expenditure.

Fetal growth restriction is defined as "A fetus that fails to reach its potential growth" (3). This is a subset of small for gestational age (SGA) fetuses. Small fetuses are divided into three groups namely a) normal (constitutionally) small. b) non placenta mediated growth restriction like structural or chromosomal anomalies, inborn errors of metabolism and intra uterine infections and so on, and c) Placenta mediated growth restriction(4). Thus it is evident that SGA is not synonymous with growth restriction and not all SGA babies are growth restricted and not all babies who are growth restricted are SGA(5). SGA is defined as an infant born with a birth weight below the $10^{\text {th }}$ centile of the population weight (4). Though this can be measured sonographycally on the fetus it is normally used in the newborn.

Unlike SGA, fetal growth restriction is detected by serial growth scanning by demonstrating stunting of growth

Senior Lecturer, Department of Obstetrics and Gynaecology, University of Peradeniya

Correspondence: Dr. D.M.C.S Jayasundara MBBS, MD, MRCOG

E mail-chandanasj@yahoo.com

Competing interests: None velocity (6). The use of customized centiles for maternal characteristics and gestation identifies small babies at a higher risk of morbidity and mortality than those identified by population centiles (7). Though the most adverse outcomes occur in fetuses with fetal growth restriction, all fetuses with SGA are at risk of increase morbidity and mortality than non SGA fetuses (4).

Once SGA is suspected it is thus important to differentiate the exact cause for it and if placenta mediated fetal growth restriction is suspected, to confirm the diagnosis and plan the follow-up and timely delivery.

\section{SCREENING AND DIAGNOSIS OF SGA}

The recognition of SGA and hence fetal growth restriction is based on accurate estimation of gestational age. This is because 'at risk' fetus is diagnosed by using a normogram based definition and the gestational age is important information for this calculation. The best method to determine the accurate gestational age is by first trimester crown rump length (CRL) using the ultrasound scan, this is accurate than the last regular menstrual date based method which is not accurate in $10-15 \%$ of pregnancies (8). Transcerebellar diameter (TCD) may be helpful in this situation as its found best to correlate with gestational age in latter trimesters of pregnancy (9). Once the dates are confirmed screening for SGA can be done and it includes obtaining a clear history to identify risk factors, examination and specific investigations. Risk factor assessment can be done at antenatal history taking and women who are at increased risk can be referred for specialized obstetric clinics for serial growth monitoring using ultrasound scan. Major risk factors with an odds ratio of $>2$ include, maternal factors like age more than
40 years, heavy smoking, cocaine use, daily vigorous exercise, previous pregnancy factors like previous SGA baby and a previous still birth, paternal factors like paternal SGA, and maternal medical conditions like chronic hypertension, diabetes with vascular disease, renal impairment, thrombophilic conditions and even maternal SGA (4). Symphysiofundal height measurement is an important screening tool used widely in our antenatal clinics, though it has been proved to have a wide variation in predictive ability to detect SGA (10). This is due to factors like fibroids, maternal obesity, liquor volume abnormalities and fetal lie and engagement can result in high intra and inter observer variability(4). This problem can be minimised by using serial measurement and plotting it on customised growth charts (11, 12). Several investigations have been proposed to detect at risk pregnancies with future SGA. Although not widely available in Sri Lanka first trimester low PAPP-A level $(<0.415$ $\mathrm{MoM}$ ) is considered a major risk factor for SGA neonate(4) and uterine artery Doppler studies in second trimester with a increased pulsatility index and diastolic notching is associated with high risk of future SGA(13).

Once it's recognized that these women have high risk of SGA it's important to follow them up to diagnose SGA. The best method to diagnose fetal size is fetal ultrasound biometry as it is known to be highly reproducible and reliable (14). Widely used parameters include bipariatal diameter (BPD), head circumference (HC), abdominal circumference $(\mathrm{AC})$ and femur length (FL) and from these measurements we can obtain a composite estimated fetal weight (EFW). Though this EFW has a method error of $7-10 \%$ (15), if plotted in growth charts together with AC these two measurements has the highest ability to predict at risk fetus with SGA and growth restriction (16). 


\section{IDENTIFYING THE AETIOLOGY OF SGA AND DIAGNOSIS OF PLACENTA MEDIATED FETAL GROWTH RESTRICTION (FGR)}

As stated above SGA can be one out of three aetiologies, constitutionally small fetus who is otherwise healthy, a non placenta mediated growth restriction and placenta mediated growth restriction. The distinction between constitutionally small fetus and a fetus who is failing to reach its growth potential and hence FGR can be done by serial monitoring of fetal growth and AC using customized growth charts (17). Due to intra and inter observer variability resulting in high false positive rate, It's recommended that these serial scans has to be done at least 3 weeks apart for accurate diagnosis of stunted fetal growth (18). Once the EFW of AC is found to be less than the $10^{\text {th }}$ centile for its gestation or if the growth rate of the fetus is lagging it's important to refer the patient for further investigations for monitoring and optimum timing of delivery as this may be due to placenta mediated growth restriction (4). Early onset SGA with severe fetal growth restriction can be due to non placenta mediated growth restriction. Common causes of non placenta mediated growth restriction include congenital abnormalities, fetal chromosomal abnormalities and fetal infections (19.20). Thus it is impotent if early onset FGR is found to refer the patient for a fetal medicine unit to exclude fetal anomalies and fetal infections like cytomegalovirus, toxoplasmosis, malaria ECT, and also refer to genetic studies for kariotyping (4).

\section{PREVENTION OF FETAL GROWTH RESTRICTION}

Commencing low dose antiplatelet medications like Asprin in patients before 16 weeks has been found to reduce the incidence of fetal growth restriction in women at risk of developing pre eclampsia (21). Though heavy smoking can lead to high risk of SGA and cessation of can reduce incidence of fetal growth restriction this is not a major problem in pregnant Sri Lankan women. Other than these interventions above there are no proven methods available to prevent fetal growth restriction (4). Thus once fetal growth restriction is diagnosed it is important to monitor these foetuses to optimize the timing of delivery as this may be the only method available to improve the neonatal morbidity and mortality (23).

\section{ANTENATAL SURVEILLANCE AND TIMING OF DELIVERY}

In the management of growth restricted fetus due to placental insufficiency we are faced with two main risks, if kept in utero when there is severe reduction on oxygen supply will lead to fetal hypoxia and death and intervening to early will lead to prematurity and its devastating complications. Thus timing of delivery is the most important decision in fetal growth restriction. To help us time the delivery careful monitoring of fetal wellbeing is of paramount importance. In addition, once fetal growth restriction is suspected in preterm fetus, it is important to consider antenatal corticosteroids if there is a risk of early delivery prior to $35+6$ days of gestation (4). As steroids are known to cause fetal heart rate abnormalities like reduced variability and number of accelerations it is important to keep this in mind when assessing fetal heart rate pattern after steroid administration (24).

Fetal wellbeing assessment is an integral management arm in growth restricted fetus as it will provide us with information on accurate timing of the delivery. Though the GRIT trial (25) which assessed whether immediate delivery after completion of steroids or continuation of pregnancy and delivery once any fetal wellbeing tests becomes abnormal or at favourable gestational age found not much difference in parinatal outcome in either method, continuation of pregnancy may be of value in extreme prematurity. Of various methods used in fetal wellbeing assessment, the most commonly used methods are Doppler flow metry (arterial and venous), cardiotocography (CTG), amniotic fluid volume evaluation, fetal biophysical profile and fetal movements.

\section{FETAL DOPPLER STUDIES}

Commonly measured fetal vessels include umbilical artery, middle cerebral artery and venous Doppler like ductus venoses and inferior vena cava. The umbilical artery Doppler (UAD) studies will give information about placental resistance; it will increase when the compliance of placental vascular bed is reduced. The pulsatility index (PI) assessment is commonly used. PI values increase as the peripheral vascular resistance increases. The diastolic flow in the umbilical artery will give us diagnostic as well as prognostic value in a growth restricted fetus as it has been found that absent or reversed end diastolic flow in umbilical artery is associated with poor perinatal outcome (26), monitoring a growth restricted fetus with umbilical artery flow studies have been proven to improve the perinatal outcome (27). Thus it is recommended that at risk fetuses of FGR to be monitored by UAD every fortnightly from 26-28 weeks and in terms of delivery if there is absent or reversed flow before 32 weeks to plan delivery by 32 weeks or early if venous Doppler are abnormal, and after 32 weeks delivery should be considered no later than 37 weeks if there is absent or reversed UAD (28). Once the UAD becomes abnormal but still there is a flow in diastole and delivery needs to be delayed for fetal indications, twice weekly Doppler is recommended and if there is absent or reversed flow is seen daily Doppler is recommended (4).

The middle cerebral artery (MCA) Doppler will provide information about the cerebral redistribution of cardiac output. The resistance in MCA will reduced as fetal adaptation for chronic hypoxia in FGR, this is called the brain sparing effect (28). Though there appear to be a relationship with abnormal MCA Doppler and fetal outcome in late onset FGR (29), its role in preterm FGR is less clear and should not be used to decide on timing of delivery (4). The ductus venoses (DV) Doppler provide information about forward cardiac function of the fetus and if there is increased resistance in DV it indicates that the fetus is at risk of cardiovascular 
deterioration (28). Especially in early onset FGR it is the strongest predictor of fetal acedaemia and death (30). The argument that UAD abnormalities are followed by MCA abnormalities and then DV abnormalities is logical and in fact there seems to be a temporal relationship in these tests. But it is not more common than any other pattern of progressive abnormalities (31). Due to the lack of concrete evidence of temporal relationship of Doppler studies in FGR a Cochrane review done on this topic has concluded "Use of more sophisticated Doppler tests like assessment of blood flow in the middle cerebral artery and ductus venosus has not been subjected to the rigorous evaluation in clinical trials so far and, therefore, cannot be recommended in routine clinical practice" (32).

Other than the Doppler studies none of the other fetal wellbeing tests have been proven to improve the perinatal outcome in morphologically normal FGR fetus when used alone for fetal surveillance, these include cardiotocography (CTG), amniotic fluid volume assessment and biophysical profile $(4,33,34,35)$. But there seems to be a place for these tests when they are used in combination with Doppler studies to improve the perinatal mortality and morbidity by helping in timing of delivery (36). When using CTG as a surveillance tool it has been found that computerized CTG (cCTG) predicted fetal academia better than traditional CTG by use of short term variation assessment but this is not available in Sri Lanka at the moment $(33,36)$.

Whatever the method used for fetal surveillance and timing the delivery, the best predictor of major morbidity and intact survival in FGR fetus without other morphological abnormalities is the gestational age at delivery and outcome was better if the fetus was 29 weeks or more at delivery $(37,38)$.

The delivery of FGR fetus should be performed in an institute where there are adequate facilities for neonatal assistance. Though there are no clear data about the mode of delivery, if the fetus is term and there is flow in the umbilical artery during diastole, the woman can be offered a vaginal delivery provided good facilities for fetal monitoring is available (4). But if there is absent or reversed diastolic flow in Doppler or if the fetus is very preterm it's more prudent to offer an elective caesarean section as the fetus may not withstand the stressors of normal labour (4).

\section{CONCLUSION}

When FGR complicates pregnancy, the perinatal outcome depends on accurate diagnosis, careful monitoring and proper timing of delivery of these fetuses. The accurate dating of pregnancy is of fundamental importance in this regard. The challenge faced by caregivers in FGR is finding causative factors that lead to abnormal placental development and finding of ways to modify this factors to minimize the occurrence of FGR. Until such time it's important that we monitor these pregnancies with careful maternal and fetal surveillance. Our aim should be to develop surveillance protocols to minimize the burden of iatrogenic prematurity with its associated high perinatal morbidity and mortality while minimizing the short and long term consequences of placental insufficiency to the fetus in uterus.

\section{REFERENCES}

1. Garite TJ, Clark R, Thorp JA. Intrauterine growth restriction increases morbidity and mortality among premature neonates. American Journal of Obstetrics and Gynecology 2004;191:481-7. doi:10.1016/j.ajog.2004.01.036.

2. Gluckman PD, Hanson MA, Cooper C, Thornburg KL. Effect of In Utero and Early-Life Conditions on Adult Health and Disease. New England Journal of Medicine 2008;359:61. doi:10.1056/ NEJMra0708473.

3. Cox S. ACOG practice bulletinIntrauterine growth restriction 2001;72:85.

4. THE INVESTIGATION AND MANAGEMENT OF THE SMALLFOR-GESTATIONAL-AGE FETUS n.d. http://jsog.org.iis2105.shared-servers. com/GuideLines/The_investigation_ and_management_of_the_small-forgestational-age_fetus.pdf (accessed 16 December 2015).
5. Soothill PW, Bobrow CS, Holmes R. Small for gestational age is not a diagnosis. Ultrasound in Obstetrics and Gynecology 1999;13:225-8. doi:10.1046/ j.1469-0705.1999.13040225.x.

6. Lee PA, Chernausek SD, HokkenKoelega ACS, Czernichow P. International small for gestational age advisory board consensus development conference statement: Management of short children born small for gestational age, april 24-October 1, 2001. PEDIATRICS 2003;111:1253-61. doi:10.1542/peds.111.6.1253.

7. Figueras F, Figueras J, Meler E, Eixarch E, Coll O, Gratacos E. Customised birthweight standards accurately predict perinatal morbidity. Archives of Disease in Childhood - Fetal and Neonatal Edition 2007;92:F277-80. doi:10.1136/ adc.2006.108621.

8. Bukowski R, Saade G, Malone FD, Porter $\mathrm{TF}$, Nyberg DA, Comstock $\mathrm{CH}$, et al. Dating of pregnancy using last menstrual period, crown-rump length, or secondtrimester ultrasound biometry: results from the faster trial. American Journal of Obstetrics \& Gynecology n.d.;189:S134. doi:10.1016/j.ajog.2003.10.262.

9. Chavez MR, Ananth CV, Smulian JC, Yeo L, Oyelese Y, Vintzileos AM. Fetal transcerebellar diameter measurement with particular emphasis in the third trimester: a reliable predictor of gestational age. Am J Obstet Gynecol 2004;191:979.

10. Morse K, Williams A, Gardosi J. Fetal growth screening by fundal height measurement. Clinical Obstetrics and Gynecology 2009;23:809.

11. Pearce J, CAMPBELL S. A comparison of symphysis-fundal height and ultrasound as screening tests for light-for-gestational age infants. BJOG 1987;94:100

12. Jong $\mathrm{CL}$, Gardosi J, Dekker GA, Colenbrander GJ, Geijn HP. Application of a customised birthweight standard in the assessment of perinatal outcome in a high risk population. BJOG 1998;105:531.

13. Cnossen JS, Morris RK, Riet G ter, Mol BW, van der Post JA, Coomarasamy $A$, et al. Use of uterine artery Doppler ultrasonography to predict pre-eclampsia and intrauterine growth restriction: a systematic review and bivariable metaanalysis. CMAJ 2008;178:701.

14. Perni S, Chervenak F, Kalish R, Magherini-Rothe S, Predanic M, Streltzoff $J$, et al. Intraobserver and interobserver reproducibility of fetal biometry. 
Ultrasound in Obstetrics \& Gynecology 2004;24:654.

15. Hadlock F, Harrist R, Carpenter R, Deter R, Park S. Sonographic estimation of fetal weight. The value of femur length in addition to head and abdomen measurements. Radiology 1984;150:535.

16. Chauhan SP, Cole J, Sanderson M, Magann EF, Scardo JA. Suspicion of intrauterine growth restriction: use of abdominal circumference alone or estimated fetal weight below $10 \%$. The Journal of Maternal-Fetal \& Neonatal Medicine 2006;19:557.

17. Owen P, Donnet ML, Ogston SA, Christie AD, Howie PW, Patel NB. Standards for ultrasound fetal growth velocity. BJOG 1996;103:60-9.

18. Mongelli M, Ek S, Tambyrajia R. Screening for fetal growth restriction: a mathematical model of the effect of time interval and ultrasound error. Obstet \& Gynecol 1998;92:908-12.

19. Niknafs P, Sibbald J. Accuracy of single ultrasound parameters in detection of fetal growth restriction. American Journal of Perinatology, 2001;18:325-34.

20. Hendrix N, Berghella V. Non-placental causes of intrauterine growth restriction. vol. 32, Seminars in Perinatology,: Elsevier; 2008, p. 161-5.

21. Bujold E, Morency A-M, Roberge S, Lacasse $Y$, Forest J-C, Giguère $Y$. Acetylsalicylic acid for the prevention of preeclampsia and intra-uterine growth restriction in women with abnormal uterine artery Doppler: a systematic review and meta-analysis. - J Obstet Gynaecol 2009;31:818-26.

22. Lumley J, Chamberlain C, Dowswell T, Oliver S, Oakley L, Watson L. Interventions for promoting smoking cessation during pregnancy. Cochrane Library, 2009.
23. Mandruzzato $G$, Meir $Y J$, Natale $R$, Maso $G$. Antepartal assessment of IUGR fetuses. Journal of Perinatal Medicine 2001;29:222-9.

24. Rotmensch S, Lev S, Kovo M, Efrat Z, Zahavi Z, Lev N, et al. Effect of betamethasone administration on fetal heart rate tracing: a blinded longitudinal study. Fetal Diagn Ther 2005;20:371-6.

25. GRIT Study Group. A randomised trial of timed delivery for the compromised preterm fetus: short term outcomes and Bayesian interpretation. BJOG 2003;110:27-32.

26. Bekedam D, Visser G, Van Der Zee A, Snijders R, Poelmann-Weesjes G. Abnormal velocity waveforms of the umbilical artery in growth retarded fetuses: relationship to antepartum late heart rate decelerations and outcome. Early Human Development 1990;24:7989.

27. Lindqvist $P$, Molin J. Does antenatal identification of small-for-gestational age fetuses significantly improve their outcome? Ultrasound in Obstetrics \& Gynecology 2005;25:258-64.

28. Mone F, McAuliffe FM, Ong S. The clinical application of Doppler ultrasound in obstetrics. The Obstetrician and Gynaecologist 2015;17:13-9.

29. Cruz-Martínez R, Figueras F, HernandezAndrade E, Oros D, Gratacos E. Fetal brain Doppler to predict cesarean delivery for nonreassuring fetal status in term small-for-gestational-age fetuses. Obstetrics and Gynaecology 2011;117:618-26.

30. Figueras F, Gratacos E. Update on the diagnosis and classification of fetal growth restriction and proposal of a stage-based management protocol. Fetal Diagnosis and Therapy 2014;36:86-98.
31. Unterscheider J, Daly S, Geary MP, Kennelly MM, McAuliffe FM, O'Donoghue $\mathrm{K}$, et al. Predictable progressive Doppler deterioration in IUGR: does it really exist? American Journal of Obstetrics and Gynecology 2013;209:539-e1.

32. Alfirevic Z, Stampalija T, Gyte GM. Fetal and umbilical Doppler ultrasound in highrisk pregnancies. The Cochrane Library 2010.

33. [33] Grivell RM, Alfirevic Z, Gyte GM, Devane D. Antenatal cardiotocography for fetal assessment. The Cochrane Library 2015.

34. [34] Zhang J, Troendle J, Meikle S, Klebanoff MA, Rayburn WF. Isolated oligohydramnios is not associated with adverse perinatal outcomes. BJOG 2004;111:220-5.

35. [35] Lalor JG, Fawole B, Alfirevic Z, Devane D. Biophysical profile for fetal assessment in high risk pregnancies. The Cochrane Library 2008.

36. [36] Turan S, Turan O, Berg C, Moyano D, Bhide A, Bower S, et al. Computerized fetal heart rate analysis, Doppler ultrasound and biophysical profile score in the prediction of acid-base status of growth-restricted fetuses. Ultrasound Obstet Gynecol 2007;30:750-6.

37. [37] Baschat AA, Cosmi E, Bilardo CM, Wolf $\mathrm{H}$, Berg C, Rigano S, et al. Predictors of neonatal outcome in earlyonset placental dysfunction. Obstetrics and Gynaecology 2007;109:253-61.

38. [38] Mari G, Hanif F, Treadwell MC, Kruger M. Gestational age at delivery and Doppler waveforms in very preterm intrauterine growth-restricted fetuses as predictors of perinatal mortality. Journal of Ultrasound Medicine 2007;26:555-9. 